Int. J. Curr. Res. Med. Sci. (2017). 3(7): 83-87

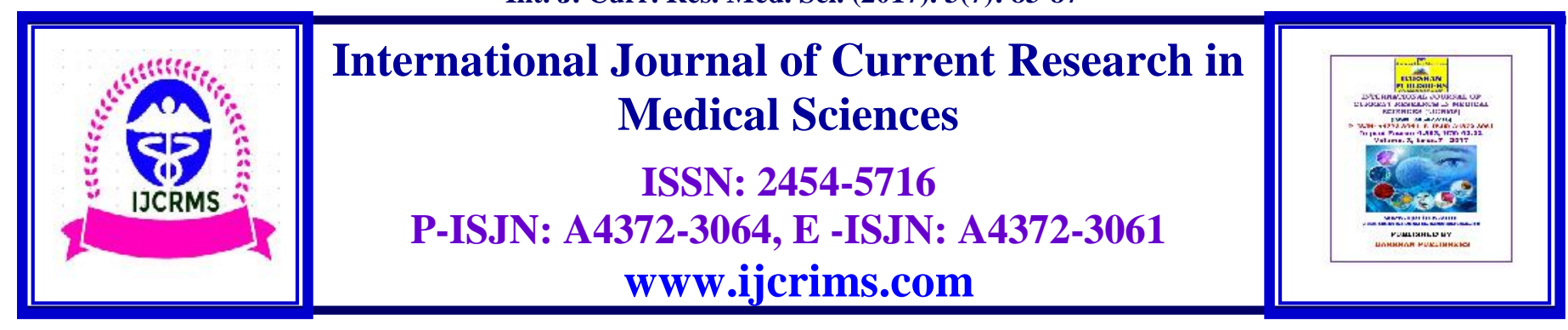

Case Report

Volume 3, Issue 7 -2017

DOI: http://dx.doi.org/10.22192/ijcrms.2017.03.07.014

\title{
Unilateral Atrophy Of Right Kidney - A Case Report
}

\author{
S.Kanimozhi ${ }^{1}$ and R.Sathish ${ }^{2 *}$ \\ ${ }^{1}$ Lecturer, Dept. Of Anatomy, Sri Sairam Siddha Medical College and research centre, \\ West Tambaram, Chennai. \\ ${ }^{2}$ Reader, Dept. Of Sattam Sarntha Maruthuvamum Nanju Maruthuvamum, \\ Sri Sairam Siddha Medical College and research centre, West Tambaram, Chennai. \\ *Corresponding Author: R.Sathish MD(s)., \\ Reader, Dept. of Sattam Sarntha Maruthuvamum Nanju maruthuvamum \\ Sri Sairam Siddha Medical College and Research Centre, \\ West Tambaram, Chennai. \\ Email: Sathizkannan@gmail.com
}

\begin{abstract}
Unilateral Atrophy of kidney may be physiological or pathological. During our routine dissection, we came across an adult male cadaver presented with a hypoplasic right kidney whereas left kidney was normal. In the right kidney the capsule was difficult to strip off \& adherent to its surface. The cut section showed thinned out cortex. Calyces were not well distinguished. The left kidney showed well demarcated cortex and medulla. No other significant anomalies were detected in other organs may confirms the cause of reduction in size of the right kidney in the present study due to congenital hypoplasia. In many people with congenital unilateral renal hypoplasia the other kidney works normally. Early detection of the atrophic kidneys is very important so as to prevent further deterioration of kidney damage.
\end{abstract}

Keywords: Kidney, Renal hypoplasia, Unilateral hypoplasia, Atrophic kidney.

\section{Introduction}

The kidneys are a pair of essential excretory and retroperitoneal organs. The mammalian kidney develops from intermediate mesoderm through a series of three successive stages: the pronephros, mesonephros, and metanephros [1]. In human, the kidney starts to develop at 5 to 6 week after fertilization. The fetal metanephric kidney begins to function by $10^{\text {th }}$ week of gestation.
They are placed on each side of vertebral column extending from T12 to L3 vertebra. The kidneys are reddish brown in colour in the fresh state. The kidneys excrete final products of metabolic activities and excess water. The right kidney is usually slightly inferior to the left. They are bean shaped with hilum directed medially. The fibrous capsule which covers it can be stripped off except 
at the hilum. The kidneys are supplied by the renal arteries from the abdominal aorta and drained by the renal veins into the inferior vena cava [2]. The kidneys are completely bounded by a delicate connective tissue in which the blood vessels, lymphatics and nerves are running.

Renal hypoplasia is a rare anomaly of the kidney in which one or both the kidneys are less developed and contain reduced number or smaller nephrons. It may be associated with normal or hyperplasia of the opposite kidney. The normal kidney may work harder to compensate and equalise the work of both the kidneys. The cause of renal hypoplasia in most cases is unknown. In majority cases it is not an inherited one, But may be due to gene mutation.

On the otherside, the kidneys can develop into macroscopic or microscopic due to infection, toxins, systemic diseases like hypertension, stenosis of renal artery etc., which may lead to one or both renal failure whereas these pathologic causes mentioned are mostly associated with the involvement of one or more systems.

\section{Case Report}

During routine dissection of cadavers for BSMS students in our college we came across a normal built adult male cadaver presented with an atrophied right kidney. Size of the right kidney was $4 \mathrm{~cm} \times 3.5 \mathrm{~cm} \times 1.3 \mathrm{~cm}$. The capsule was difficult to strip off $\&$ adherent to its surface.

Surface of the kidney appeared and uneven. The cut section showed thinned out cortex. The cortex and medulla were found to be ill defined. Calyces were not well distinguished. The kidney was supplied by a single renal artery branching into three at the hilum . But the branches are slightly narrower compared to the left.

Left kidney is normal $(10 \mathrm{~cm} \times 4 \mathrm{~cm} \times 1 \mathrm{~cm})$. The Left kidney showed well demarcated cortex and medulla on cut section.

Clinically unilateral renal hypoplasia may not only predispose to urinary infection but can also be a cause of hypertension even in absence of secondary inflammatory changes or scarring (7).

However the etiological enquiry remained unknown in most of the cases.

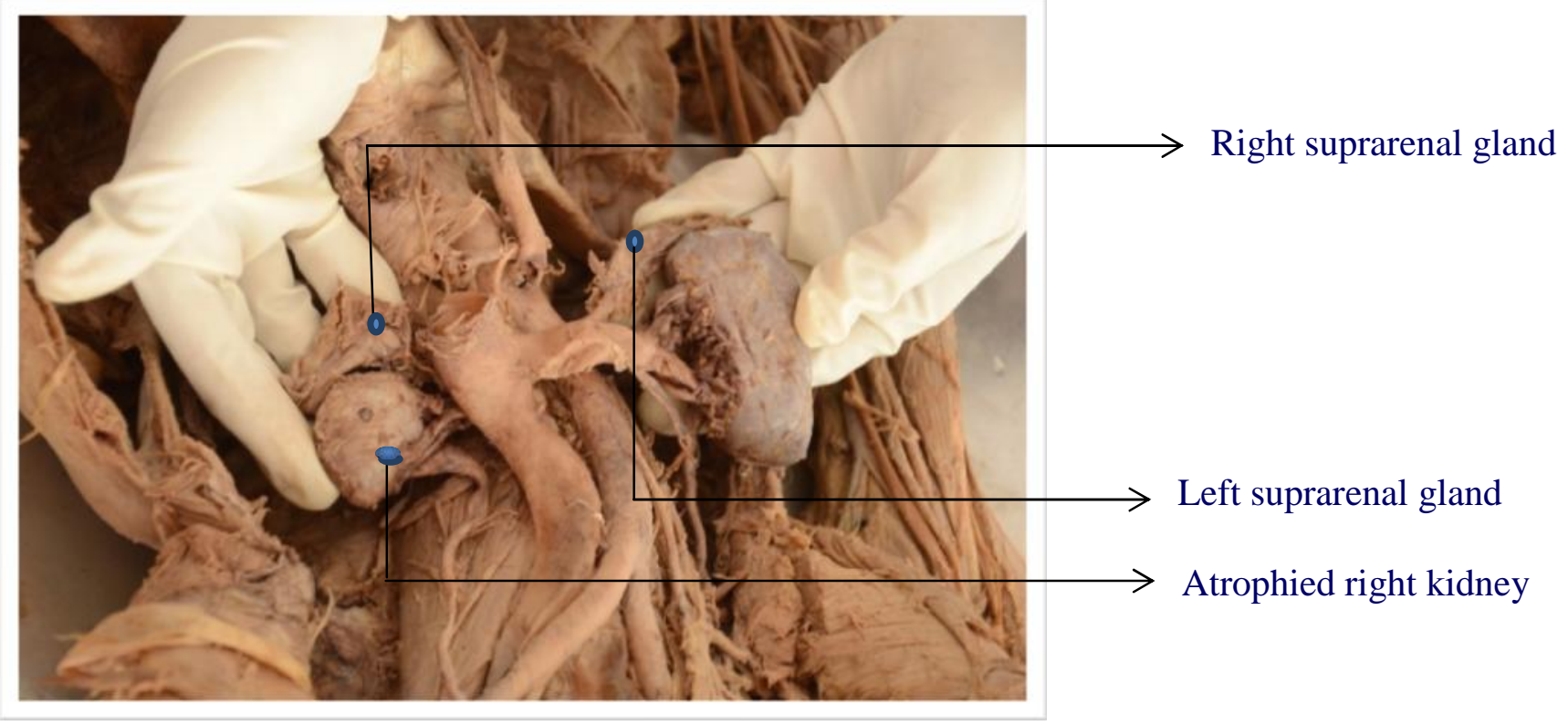

Figure- 1 Photography showing: Both kidneys with normal suprarenal gland. The right kidney shows hypoplasia. 
Int. J. Curr. Res. Med. Sci. (2017). 3(7): 83-87

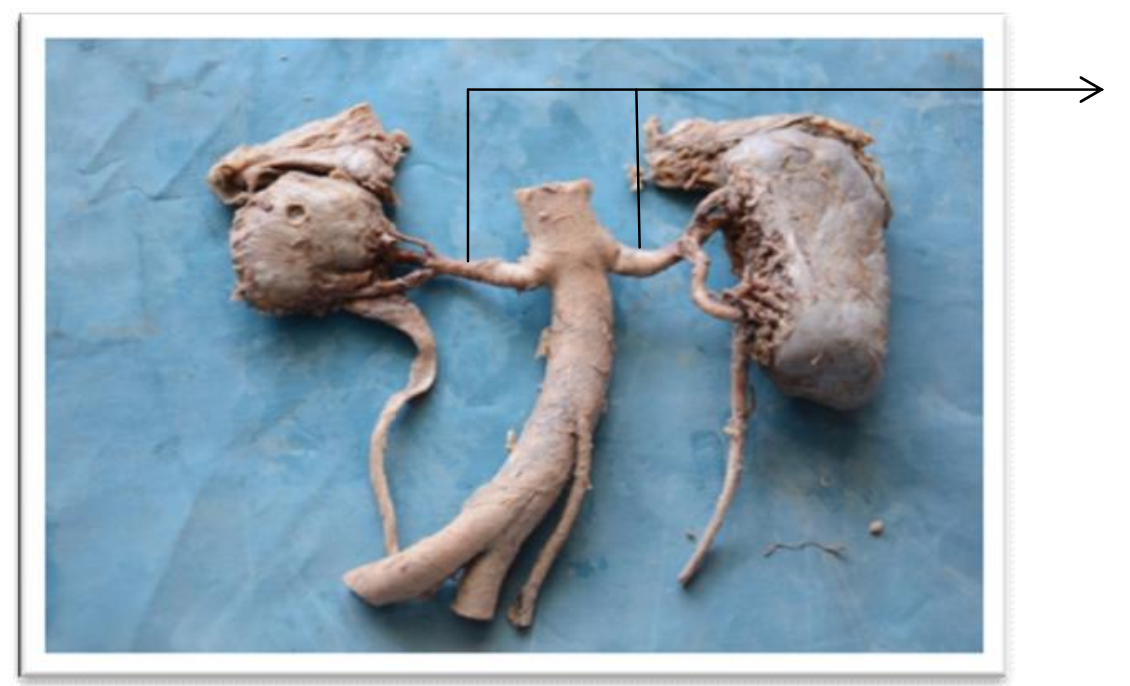

Renal arteries

Figure- 2 Gross photography of unilateral renal hypoplasia.

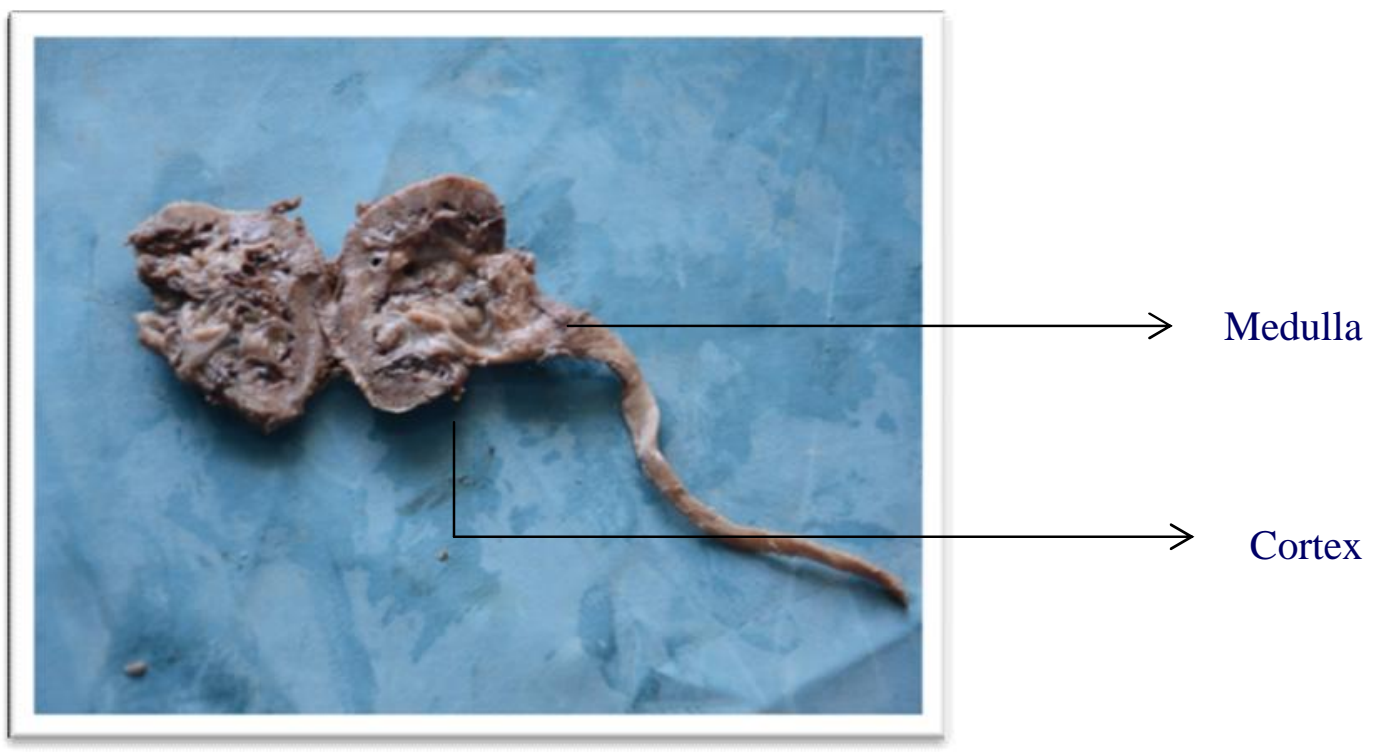

Figure - 3 Photography showing the longitudinal section of the right kidney. The cortex and medulla are not well defined and the calyxes are not distinguished correctly.

\section{Discussion}

Normal size of the kidneys is $8.1-11 \mathrm{~cm}$ in length, $5.5-7 \mathrm{~cm}$ in width and $4-5 \mathrm{~cm}$ in thickness [3]. In adult males, the kidney weighs between 125 and 170 grams. In females the weight of the kidney is between 115 and 155 grams. A kidney may be small in the conditions of congenital hypoplasia or pyelonephritic shrinkage or as a combination of both [4].

Renal hypoplasia refers to a congenitally small kidney where there is essentially normal residual parenchyma but smaller calyces, lobules and papillae [5]. This is in addition may show reduction in number and size of parenchymal cells of the organ, or its parts.

The occurrence of unilateral small kidneys has been found to be about one in 500 autopsies [4]. Thereby, atrophying of the kidneys maybe associated to deterioration of renal functions. The presence of small kidney may suggest that the patient have developed renal insufficiency or even kidney failure. The other kidney may grow larger to do the work of two kidneys. 
Renal Hypoplasia can be divided into two types, unilateral or bilateral Renal Hypoplasia. Clinically unilateral renal hypoplasia may also be influenced by the infection and can be a cause of hypertension even in absence of secondary inflammatory changes in the parenchymal cells. [3]

Atrophy may be physiological or pathological. Small atrophic kidney may be due to atherosclerosis of renal artery [6]. Size may also be reduced and scarred because of pre existing arterial narrowing or stenosis [7]. Using the Xenon washout technique, [8] a decrease in the size of the kidney correlated with a decrease in function and in the renal blood flow to the cortex has been recorded.

For a patient with atrophic kidney, firstly it will be considered whether an inborn disorder such as renal arterial narrowing or congenital renal hypoplasia or dysplasia has caused the condition. A unilateral atrophic kidney is often detected when one seeks for examinations due to high blood pressure and waist soreness.

In the urological and pathological sciences to describe the unilateral abnormally small kidney, many confusing terms have arisen such as Atrophic kidney, Contracted kidney, congenital hypoplasia, Aplastic kidney, Infantile Kidney. From the article written by Gutierrez in 1933, it has been mentioned that congenital hypoplastic kidney can also be the site of pyelonephritis.

\section{Conclusion}

In the present case the right kidney is small when compared to left which confirm the unilateral congenital hypoplasia since no other significant anomaly was seen in rest of the organs. It could also be linked with problems in the synthesis of growth factors or their receptors during fetal development and gene mutation. A child with congenital renal hypoplasia may develop hypertension later in life. By leading a healthy lifestyle with healthy diet and plenty of exercise may reduce the risk of hypertension. Early detection of the atrophic kidneys is very important so as to prevent further deterioration of kidney damage. This study could be further confirmed with histopathological examination.

\section{References}

1. Dutta A K. The Urinary System . In Dutta AK(ed). Essentials of Human Anatomy, Part I, 8thedition, Kolkata, Current Books International, 2009; 289

2. Henry gray, Gray's Anatomy The anatomical basis of clinical practice - $38^{\mathrm{h}}$ edition Dutta A K. The Urinary System. In Dutta AK(ed). Essentials of Human Anatomy, Part I, 8thedition, Kolkata, Current Books International, 2009; 289

3. A. Risdon , L. W. Young, A. R. Chrispin ,Renal hypoplasia and dysplasia: A radiological and pathological correlationR. Pediatric RadiologyDecember 1975, Volume 3 , Issue 4

4.C. Bengtsson B. Hood , The unilateral small kidney with special reference to the hypoplastic kidney Review of the literature and authors' points of view International urology \&nephrology December 1971, Volume 3, Issue 4,pp 337-351

5.Fillastre JP, Herment C, Monconduit M, Grall M. Sem Hop.Unilateral renal atrophy]. 1975 Mar 2051(14):951-7.

6. Mohan H . The Kidney and lower Urinary Tract.In Mohan $\mathrm{H}$ (ed) Text book of Pathology, $6^{\text {th }}$ edition, New Delhi, Jaypee Brothers, 2010; 653- 666

7.M. McLachlan, M.D., , and P. Wasserman , radiation oncology and all related sciences Changes in sizes and distensibility of the aging kidney may 2014 An international journal journal of Radiology, The British Institute of Radiology

8.Norman K. Hollenberg, Douglass F. Adams, Harold S. Solomon, Abdur Rashid, Herbert L. Abrams, and John P. Merrill Senescence and the Renal Vasculature in Normal Man, 1974

9. Lee McGregor's synopsis of surgical anatomy $12^{\text {th }}$ edition. 
10.Atrophic pyelonephritis versus congenital renal hypoplasia John L. Emmett, M.D.; J.

Jose Alverez- Ierena, M.D.; John R. McDonald, M.D. Author Affiliations JAMA.

1952;148(17):1470-1477.

doi:10.1001/jama.1952.02930170010003.

\begin{tabular}{|l|l|}
\hline \multicolumn{2}{|c|}{ Access this Article in Online } \\
\hline & \\
\hline
\end{tabular}

How to cite this article:

S.Kanimozhi and R.Sathish. (2017). Unilateral Atrophy Of Right Kidney - A Case Report. Int. J. Curr. Res. Med. Sci. 3(7): 83-87.

DOI: http://dx.doi.org/10.22192/ijcrms.2017.03.07.014 